\title{
Bazo accesorio como hallazgo incidental en autopsia médico legal
}

\section{Accessory spleen as incidental find in legal medical autopsy}

https://doi.org /10.5377/rcfh.v6i1.9943

Dr. Jorge Luis Pérez Maldonado ${ }^{1}$

${ }^{1}$ Departamento de Patología Forense, Dirección de Medicina Forense, Tegucigalpa

Correspondencia a: jlperezmldnd@gmail.com Recibido: 07 de febrero 2020 Aceptado: 20 de febrero 2020

Citar como: Pérez JL. Bazo accesorio como hallazgo incidental en autopsia médico legal. Rev. Cienc. Forenses Honduras, 2020; 6(1)28

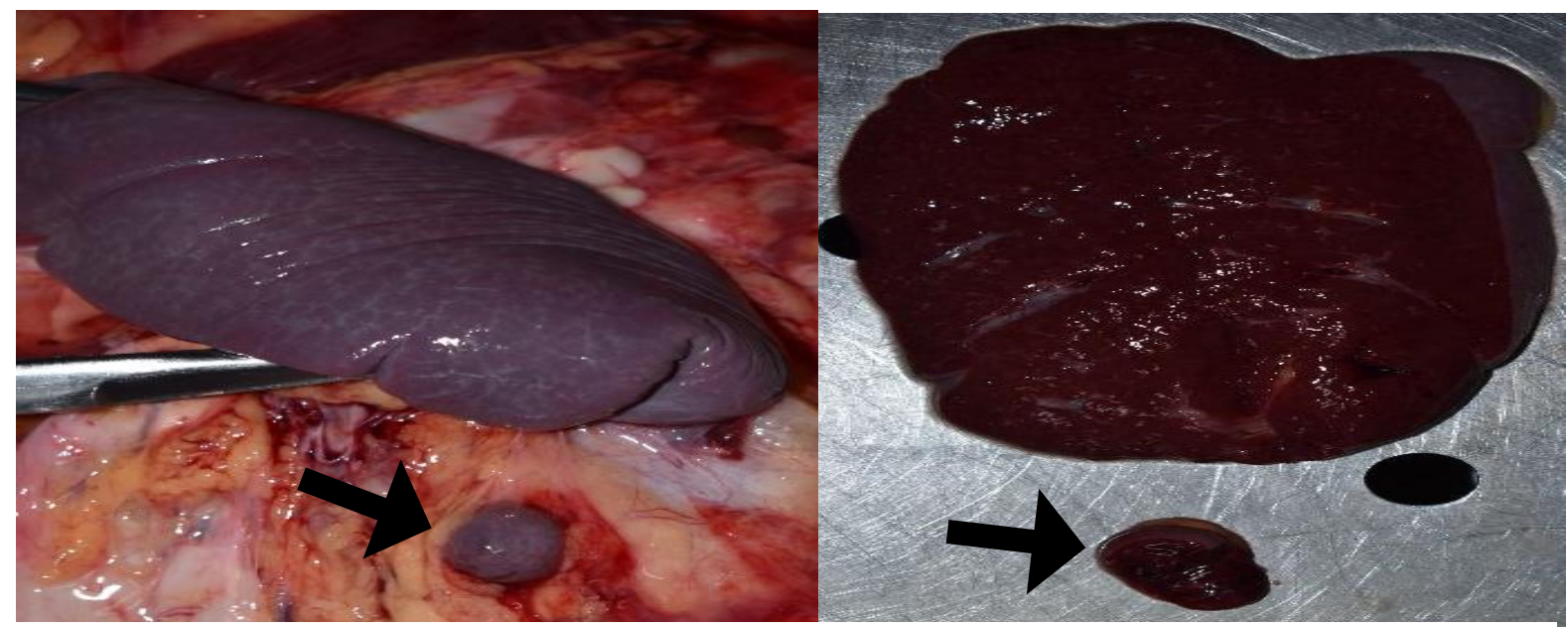

Figura 1. Bazo accesorio en cavidad abdominal (Flecha) Figura 2. Superficie de corte de ambos

Femenina de 17 años de edad, cuya causa de muerte fue hemotórax secundario a laceración cardiaca por herida con arma de fuego. En la autopsia medicolegal se observó, en el cuadrante superior izquierdo del abdomen la presencia de dos masas separadas, de tejido esplénico, con capsula gruesa, una de $10 \mathrm{~cm}$ de longitud y $140 \mathrm{~g}$ de peso y otra de $2 \mathrm{~cm}$ de longitud y $5 \mathrm{~g}$ de peso. Determinándose por características macroscópicas e histopatológicas que la estructura de dos centímetros correspondía a "bazo accesorio". El bazo accesorio, o supra numerario como también se le conoce, es una condición benigna, muchas veces asintomática, considerada como una variante anatómica que se da por un defecto de fusión durante la embriogénesis ${ }^{1}$. La presencia de bazos accesorios en la cavidad abdominal es relativamente frecuente (10-15\% de la población general) ${ }^{2}$. Es importante diferenciar esta entidad de la esplenosis, esta última se define como el autotrasplante de tejido esplénico en la cavidad peritoneal en pacientes con antecedentes de lesión traumática esplénica o esplenectomía; el tejido "separado" secuestra una nueva red de irrigación sanguínea, funcionando de manera autónoma; histológicamente se diferencian, ya que en la esplenosis hay carencia de elementos como ser una capsula gruesa, músculo liso y encontramos angiogénesis, mientras que la estructura del bazo accesorio es la misma que la del bazo único ${ }^{3}$.

\section{Referencias Bibliográficas}

1.Trinci M, lanniello S, Galluzzo M, Giangregorio C, Palliola R, Briganti V, Tursini S, Miele V. A rare case of accessory spleen torsion in a child diagnosed by ultrasound (US) and contrast-enhanced ultrasound (CEUS). J Ultrasound. 2019; 22(1):99-102.

2. Acevedo JA, Caballero JG, Cona J, Cabaleiro PM, Lencinas A, Cordoba M. Bazo accesorio intrapancreático que imita tumor de cola de páncreas. Rev Argent Cir. 2017;109(4): 1-10.

3. Calderón MA, Silva LC, Fernández J, Ordóñez A, Carrillo JA. Esplenosis abdominopélvica: Presentación de un caso y revisión de la literatura. Rev Colomb Radiol. 2017;28(4):4825-7. 